\title{
Power and Limitations of Biochemical Methane Potential (BMP) Tests
}

\author{
Konrad Koch ${ }^{1 *}$, Sasha D. Hafner ${ }^{2}$, Sören Weinrich ${ }^{3}$, Sergi Astals ${ }^{4}$ and Christof Holliger ${ }^{5}$ \\ ${ }^{1}$ Chair of Urban Water Systems Engineering, Technical University of Munich, Garching, Germany, ${ }^{2}$ Department of \\ Engineering, Aarhus University, Aarhus, Denmark, ${ }^{3}$ Biochemical Conversion Department, Deutsches \\ Biomasseforschungszentrum gemeinnützige GmbH, Leipzig, Germany, ${ }^{4}$ Department of Chemical Engineering and Analytical \\ Chemistry, University of Barcelona, Barcelona, Spain, ${ }^{5}$ Laboratory for Environmental Biotechnology, Ecole Polytechnique \\ Fédérale de Lausanne, Lausanne, Switzerland
}

Keywords: anaerobic digestion, biogas, biochemical methane potential tests, batch vs. continuous feeding mode, synergistic and antagonistic effects

\section{INTRODUCTION}

As energy systems transition toward renewable sources, anaerobic digestion (AD), which can be used to recover energy from organic substrates, is receiving growing attention. $\mathrm{AD}$ research and practice both rely on biochemical methane potential (BMP) tests to determine the methane potential of sewage sludge, energy crops and organic wastes (Pearse et al., 2018). In contrast to

\section{OPEN ACCESS}

Edited by:

Daniel Puyol,

Rey Juan Carlos University, Spain

Reviewed by:

Ao Xia,

Chongqing University, China Obulisamy Parthiba Karthikeyan, University of Houston, United States

*Correspondence: Konrad Koch k.koch@tum.de

Specialty section: This article was submitted to Bioenergy and Biofuels, a section of the journal Frontiers in Energy Research

Received: 19 December 2019 Accepted: 01 April 2020

Published: 23 April 2020

Citation: Koch K, Hafner SD, Weinrich S, Astals S and Holliger C (2020) Power and Limitations of Biochemical Methane Potential (BMP) Tests.

Front. Energy Res. 8:63. doi: $10.3389 /$ fenrg.2020.00063 continuous reactor experiments, BMP tests are batch, and can be conducted without a major investment of equipment, labor and time. However, this and other differences limit the applicability of results from a BMP test to full-scale plant operation. Yet even in the peer-reviewed literature, BMP test results are not always used appropriately. An example is the determination of synergistic or antagonistic effects during anaerobic co-digestion in substrate mixtures. A BMP test is a powerful and useful tool, but it is important to recognize the type of questions that can and cannot be answered with this experimental setup. Clarification of these issues is the objective of the present contribution.

\section{DISCUSSION}

The idea of a BMP test was first described by Owen et al. (1979). By design, a BMP test measures "the biodegradability of material subjected to anaerobic treatment" (Owen et al., 1979). The original approach was further developed and refined afterwards (Angelidaki and Sanders, 2004; Angelidaki et al., 2009; VDLUFA, 2011; Holliger et al., 2016; VDI 4630, 2016; Filer et al., 2019). Now, four decades later, several companies sell complete automated BMP test equipment, which led to a widespread use of BMP tests in $\mathrm{AD}$ research and practice. For the following discussion, it is assumed that the BMP test is conducted correctly following the latest guidelines (Holliger et al., 2016; VDI 4630, 2016).

Whether or not a BMP test is a suitable method depends strongly on the problem statement an experiment is meant to address. This topic has been discussed before (VDI 4630, 2016) and has been further developed here.

\section{APPROPRIATE APPLICATIONS OF BMP TESTS}

The BMP is the maximum amount of methane that can be recovered from a substrate per mass of substrate organic matter as volatile solids (VS) or chemical oxygen demand (COD). Determination 
of the BMP of a substrate or a mixture is the most common reason to conduct a BMP test. Similarly, BMP tests are one option to measure the impact of a pre-treatment on substrate's degradability, although the transferability to continuously operated systems is questionable (Janke et al., 2019). Providing optimal conditions for the $\mathrm{AD}$ process is key in order to achieve the highest possible degree of degradation. Therefore, the conditions applied in a BMP test aim at the best possible environment for microbial growth. This includes using inoculum from a well-functioning digester (Raposo et al., 2011), including a positive control (such as microcrystalline cellulose) to check the performance of the inoculum (VDLUFA, 2011; Holliger et al., 2016), choosing a suitable inoculum-to-substrate ratio (ISR) to avoid both over- or under-loading of the process (Koch et al., 2019), providing a suitable and constant temperature combined with a gentle mixing, and removing the oxygen from the headspace by flushing with an inert gas prior to incubation (Koch et al., 2015a). Additionally, tests continue until methane production rate is very low to avoid an underestimation of the BMP due to only partial degradation of slowly degradable substrates (Holliger et al., 2016). By definition, the methane yield achieved in continuous experiments or in full-scale plants should usually be lower compared to the value obtained in a BMP test (Holliger et al., 2017). This is implied by the word biochemical methane potential.

Related to the BMP is the anaerobic biodegradability of a substrate (Jensen et al., 2011), which is obtained by dividing the obtained experimental BMP by a corresponding theoretical value. This theoretical value is usually calculated based on the stoichiometry of the $\mathrm{AD}$ process according to the elemental composition of the substrate (Buswell and Mueller, 1952). The elemental composition of a substrate can be either measured directly or inferred from macromolecular analysis (e.g., carbohydrates, proteins, lipids) or even by a detailed forage analysis (Van Soest et al., 1991), as it allows to further distinguish between easily, hardly and non-digestible substrate components (Angelidaki and Sanders, 2004). For liquid and sludge samples, the theoretical value can be calculated based on the COD and the theoretical methane yield of COD, i.e., $0.35 \mathrm{~L}_{\mathrm{CH} 4} / \mathrm{g}_{\mathrm{COD}}$ (Buffiere et al., 2006). Determine the COD of particulate organic matter is also possible, but difficult (Noguerol-Arias et al., 2012). These approaches are based on the same principles of redox chemistry and expected values are identical. For realistic approximation of anaerobic biodegradability, even if the organic matter is $100 \%$ biodegradable anaerobically, only about $90 \%$ will be transformed into methane since about $10 \%$ will be utilized for microbial biomass production (Rittmann and McCarty, 2001; VDI 4630, 2016).

BMP tests allow to evaluate the anaerobic degradation of the substrate, but can only give a first indication for the degradation kinetics owing to the different operation modes between BMP tests and continuously operated experiments as well as due to the sensitivity to ISR and inoculum adaptation. Obtained kinetic parameters, such as the hydrolysis constant $\left(\mathrm{k}_{\mathrm{hyd}}\right)$, when assuming that the hydrolysis is the rate-limiting step (Pavlostathis and Giraldo-Gomez, 1991), allow only for a qualitative assessment of the $\mathrm{AD}$ process in a continuous process. Hydrolysis constants estimated in BMP tests are typically lower (slower) than those observed in continuous operation. This can been attributed to the batch operation with a high initial organic load and the potential necessity of inoculum acclimation (Batstone et al., 2009; Jensen et al., 2011; Peces et al., 2018). Hence, for a more precise determination, continuous experiments are strongly recommended (Weinrich et al., 2018).

Furthermore, BMP tests might be used for the detection of acute toxicity of an inhibitor present in the substrate or mutually added. It is of utmost importance to consider the high ratio of inoculum compared to the substrate, particularly for energy-rich substances. For microcrystalline cellulose for instance, typically $<10 \mathrm{~g}$ of substrate is provided per $\mathrm{kg}$ of inoculum (1\% on a wet weight mass basis), showing quite plainly the potentially extreme dilution effect in BMP tests. Hence, detecting an inhibition by a substrate in a BMP test already indicates strong acute toxicity. When testing the inhibitory effect of a mutually added substance, the final concentration in the assay considering the addition of inoculum has to be kept in mind. However, inhibition assays, also known as anaerobic toxicity assays, are the preferred experimental platform to quantify the toxicity of a compound on the anaerobic digestion process and the methanogens in particular (Owen et al., 1979; Astals et al., 2015).

\section{INAPPROPRIATE APPLICATIONS OF BMP TESTS}

Synergistic or antagonistic effects linked to a better nutrient balance in the anaerobic co-digestion of two or more substrates cannot be studied using BMP tests (VDI 4630, 2016). When conducted correctly, co-digestion results in a BMP for the mixture close to the weighted average of individual substrates (Koch et al., 2015b; Ebner et al., 2016; Thorin et al., 2018; Kim et al., 2019). For a BMP test, substrate(s) are mixed with inoculum at a VS-based ISR between 1 and 4 depending on the expected degradability of the substrate (Holliger et al., 2016). Particularly for substrates with a high energy density (i.e., high concentration of biodegradable VS), the mass fraction of substrate compared to inoculum (fresh mass basis) may be a few percentages. A healthy inoculum sourced from a well-functioning digester typically provides all necessary inorganic nutrients and trace elements the substrate might lack. Therefore, a change of the macronutrients (e.g., $\mathrm{C} / \mathrm{N}$ ratio) or in the concentration of trace elements in the substrate will only have a negligible impact on the ratio/concentration in the mixture. A good example of this is the degradation of cellulose, which is commonly used as a positive control in BMP tests. Although it is composed of only carbon, hydrogen and oxygen and lacks nitrogen, phosphorous, and other essential elements, cellulose is well-degraded in BMP tests. When apparent synergism or antagonism is found by comparing different substrate mixtures in BMP tests, it should instead be taken as an indicator that either the test design and execution was improper or the inoculum was insufficiently diverse or lacking some nutrients.

BMP tests are unable to provide information on chronic toxicity due to a toxicant present in the substrate or added independently. The reasons are the high proportion of inoculum in the test mixture as well as the fact that the substance is only 
TABLE 1 | Power and limitations of BMP test. Is a BMP test suitable for the following applications?

\begin{tabular}{|c|c|}
\hline YES & NO \\
\hline$\checkmark$ Biochemical methane potential (BMP) of a substrate or mixture & $\begin{array}{l}\times \text { Synergistic or antagonistic effects in co-digestion of substrate mixtures, by the } \\
\text { addition of trace elements, etc. }\end{array}$ \\
\hline$\checkmark$ Anaerobic biodegradability (by dividing the obtained BMP by a theoretical value) & $\times$ Long-term effects of nutrients or trace elements due to monotonic feeding \\
\hline$\checkmark$ Acute toxicity of an inhibitor present in the substrate or mutually added & $\times$ Chronic toxicity of an inhibitor present in the substrate or mutually added \\
\hline$\checkmark$ Qualitatively describing the kinetic of the AD process & $\begin{array}{l}\times \text { Methane yield, process stability and achievable organic loading rate in a } \\
\text { continuously operated system }\end{array}$ \\
\hline
\end{tabular}

fed once at the beginning of the test. In this mode of operation, any potential toxicant does not reach steady-state levels in the mixed liquor over time. While continuous experiments are one option to study chronic toxicity, repeated re-feeding of the assay once the stable plateau phase of the methane production is reached is another one (Patsalou et al., 2019). Also, due to the short test duration, BMP tests cannot assess the capability of the anaerobic microbial community to adapt to the inhibitor over time (Astals et al., 2015).

For a well-functioning AD process, the microbial community has to be supplied with enough macronutrients and essential trace elements in a bioavailable form. A monotonic substrate spectrum can lead to a washout of required trace elements or to an accumulation of inhibiting or even toxic substances in the long-term. Effects of washout or accumulation can, logically, only be observed under a continuous feeding regime and hence, not in regular BMP tests with one single feeding event at the beginning. It has to be noted that such effects are potentially detected only after many hydraulic retentions times (Lebuhn et al., 2008).

Finally, the batch-mode operation of a BMP test also does not allow any conclusions about the actual (vs. potential) methane yield, the process stability, the achievable organic loading rate (OLR) and related to that, the necessary hydraulic retention time (HRT) in a continuously operated system. By providing optimal digestion condition, a BMP test is designed to achieve the maximum possible methane yield of a substrate (i.e., BMP). Depending on OLR, HRT, digester concept, temperature, etc., the methane yield achieved in continuously operated systems is by definition below the BMP, since this value is the maximum achievable yield. A higher specific methane yield found in a continuous experiment compared to the BMP is a clear indication of improper conditions in the BMP test, such as an unsuitable inoculum or a too short duration of the test. Similar to the effects of washout or accumulation discussed above, no conclusions about the process stability of the $\mathrm{AD}$ process in continuous mode can be based on BMP tests. Typical parameters for the design of digesters, such as OLR and HRT, can only be deduced from continuous experiments, simplified mass balances and reaction models (VDI 4630, 2016; Weinrich et al., 2018) or from experiences in plants operating under similar conditions.

\section{CONCLUSIONS}

BMP tests are a powerful and useful tool in $\mathrm{AD}$ research and practice. They can be applied for the experimental determination of the BMP of a pure or mixed substrate. Based on the BMP, the anaerobic biodegradability can be estimated by dividing the obtained BMP by a theoretical value. Kinetic parameters achieved from BMP tests allow for a qualitative evaluation of the process kinetics. While acute toxicity of an inhibitor present in the substrate or mutually added can be detected in BMP tests, this is not possible for chronic toxicity. As in contrast to continuously operator systems, the substrate in a BMP test is only added once, and owing to the typically high share of inoculum present in the assay, synergistic or antagonistic occurring in codigestion BMP tests can be different from those occurring in continuous processes. BMP tests cannot be utilized to assess long-term effects of nutrients or trace elements availability due to monotonic feeding. Similarly, the methane yield, the process stability and the achievable organic loading rate in a continuously operated system cannot be elucidated by BMP tests. A summary of the power and limitations of BMP tests can be found in Table 1.

\section{AUTHOR CONTRIBUTIONS}

KK identified the necessity of the present statement, wrote the manuscript draft, and revised it according to the others' comments. SH, SW, SA, and $\mathrm{CH}$ contributed to the discussion of the topic, augmented the outline, participated in writing the manuscript, and revising it critically.

\section{FUNDING}

This work was supported by the German Research Foundation (DFG) and the Technical University of Munich (TUM) in the framework of the Open Access Publishing Program. The financial support of the TUM Global Incentive Fund to host the second international workshop on standardization of BMP tests in Freising (Germany) in 2018 is highly appreciated. SA is grateful to the Spanish Ministry of Science, Innovation and Universities for his Ramon y Cajal fellowship (RYC-2017-22372). SW is thankful to the German Federal Ministry of Food and Agriculture by funding the research project Evaluating substrates for biogas production - From laboratory to industrial scale (Grant 22034614). The Swiss Federal Office for Energy has generously financially supported the first international workshop on standardization of BMP tests in Leysin (Switzerland) in 2015 and the two international inter-laboratory studies. 


\section{REFERENCES}

Angelidaki, I., Alves, M., Bolzonella, D., Borzacconi, L., Campos, J. L., Guwy, A. J., et al. (2009). Defining the Biomethane Potential (BMP) of solid organic wastes and energy crops: a proposed protocol for batch assays. Water Sci. Technol. 59, 927-934. doi: 10.2166/wst.2009.040

Angelidaki, I., and Sanders, W. (2004). Assessment of the anaerobic biodegradability of macropollutants. Rev. Environ. Sci. Biotechnol. 3, 117-129. doi: 10.1007/s11157-004-2502-3

Astals, S., Batstone, D. J., Tait, S., and Jensen, P. D. (2015). Development and validation of a rapid test for anaerobic inhibition and toxicity. Water Res. 81, 208-215. doi: 10.1016/j.watres.2015.05.063

Batstone, D. J., Tait, S., and Starrenburg, D. (2009). Estimation of hydrolysis parameters in full-scale anerobic digesters. Biotechnol. Bioeng. 102, 1513-1520. doi: 10.1002/bit.22163

Buffiere, P., Loisel, D., Bernet, N., and Delgenes, J.-P. (2006). Towards new indicators for the prediction of solid waste anaerobic digestion properties. Water Sci. Technol. 53, 233-241. doi: 10.2166/wst.2006.254

Buswell, A. M., and Mueller, H. F. (1952). Mechanism of methane fermentation. Ind. Eng. Chem. 44, 550-552. doi: 10.1021/ie50507a033

Ebner, J. H., Labatut, R. A., Lodge, J. S., Williamson, A. A., and Trabold, T. A. (2016). Anaerobic co-digestion of commercial food waste and dairy manure: characterizing biochemical parameters and synergistic effects. Waste Manag. 52, 286-294. doi: 10.1016/j.wasman.2016.03.046

Filer, J., Ding, H. H., and Chang, S. (2019). Biochemical Methane Potential (BMP) assay method for anaerobic digestion research. Water 11:921. doi: $10.3390 /$ w1 1050921

Holliger, C., Alves, M., Andrade, D., Angelidaki, I., Astals, S., Baier, U., et al. (2016). Towards a standardization of biomethane potential tests. Water Sci. Technol. 74, 2515-2522. doi: 10.2166/wst.2016.336

Holliger, C., Fruteau de Laclos, H., and Hack, G. (2017). Methane production of full-scale anaerobic digestion plants calculated from substrate's biomethane potentials compares well with the one measured on-site. Front. Energy Res. 5:12. doi: 10.3389/fenrg.2017.00012

Janke, L., Weinrich, S., Leite, A. F., Sträuber, H., Nikolausz, M., Nelles, M., et al. (2019). Pre-treatment of filter cake for anaerobic digestion in sugarcane biorefineries: assessment of batch versus semi-continuous experiments. Renew. Energy 143, 1416-1426. doi: 10.1016/j.renene.2019.05.029

Jensen, P. D., Ge, H., and Batstone, D. J. (2011). Assessing the role of biochemical methane potential tests in determining anaerobic degradability rate and extent. Water Sci. Technol. 64, 880-886. doi: 10.2166/wst.2011.662

Kim, J., Kim, J., and Lee, C. (2019). Anaerobic co-digestion of food waste, human feces, and toilet paper: methane potential and synergistic effect. Fuel 248, 189-195. doi: 10.1016/j.fuel.2019.03.081

Koch, K., Bajón Fernández, Y., and Drewes, J. E. (2015a). Influence of headspace flushing on methane production in Biochemical Methane Potential (BMP) tests. Bioresour. Technol. 186, 173-178. doi: 10.1016/j.biortech.2015.03.071

Koch, K., Hafner, S. D., Weinrich, S., and Astals, S. (2019). Identification of critical problems in Biochemical Methane Potential (BMP) tests from methane production curves. Front. Environ. Sci. 7:178. doi: 10.3389/fenvs.2019.00178

Koch, K., Helmreich, B., and Drewes, J. E. (2015b). Co-digestion of food waste in municipal wastewater treatment plants: effect of different mixtures on methane yield and hydrolysis rate constant. Appl. Energy 137, 250-255. doi: 10.1016/j.apenergy.2014.10.025

Lebuhn, M., Liu, H., Heuwinkel, H., and Gronauer, A. (2008). Biogas production from mono-digestion of maize silage-long-term process stability and requirements. Water Sci. Technol. 38, 1645-1651. doi: 10.2166/wst. 2008.495
Noguerol-Arias, J., Rodríguez-Abalde, A., Romero-Merino, E., and Flotats, X. (2012). Determination of chemical oxygen demand in heterogeneous solid or semisolid samples using a novel method combining solid dilutions as a preparation step followed by optimized closed reflux and colorimetric measurement. Anal. Chem. 84, 5548-5555. doi: 10.1021/ac3003566

Owen, W. F., Stuckey, D. C., Healy, J. B. Jr.. Young, L. Y., and McCarty, P. L. (1979). Bioassay for monitoring biochemical methane potential and anaerobic toxicity. Water Res. 13, 485-492. doi: 10.1016/0043-1354(79)90043-5

Patsalou, M., Samanides, C. G., Protopapa, E., Stavrinou, S., Vyrides, I., and Koutinas, M. (2019). A citrus peel waste biorefinery for ethanol and methane production. Molecules 24:2451. doi: 10.3390/molecules24132451

Pavlostathis, S. G., and Giraldo-Gomez, E. (1991). Kinetics of anaerobic treatment: a critical review. Crit. Rev. Environ. Control 21, 411-490. doi: $10.1080 / 10643389109388424$

Pearse, L. F., Hettiaratchi, J. P., and Kumar, S. (2018). Towards developing a representative biochemical methane potential (BMP) assay for landfilled municipal solid waste - a review. Bioresour. Technol. 254, 312-324. doi: 10.1016/j.biortech.2018.01.069

Peces, M., Astals, S., Jensen, P. D., and Clarke, W. P. (2018). Deterministic mechanisms define the long-term anaerobic digestion microbiome and its functionality regardless of the initial microbial community. Water Res. 141, 366-376. doi: 10.1016/j.watres.2018.05.028

Raposo, F., Fernández-Cegrí, V., De la Rubia, M. A., Borja, R., Béline, F., Cavinato, C., et al. (2011). Biochemical methane potential (BMP) of solid organic substrates: evaluation of anaerobic biodegradability using data from an international interlaboratory study. J. Chem. Technol. Biotechnol. 86, 1088-1098. doi: $10.1002 / j \mathrm{ctb} .2622$

Rittmann, B. E., and McCarty, P. L. (2001). Environmental Biotechnology: Principles and Applications. New York, NY: McGraw-Hill Education.

Thorin, E., Olsson, J., Schwede, S., and Nehrenheim, E. (2018). Co-digestion of sewage sludge and microalgae - biogas production investigations. Appl. Energy 227, 64-72. doi: 10.1016/j.apenergy.2017.08.085

Van Soest, P. J., Robertson, J. B., and Lewis, B. A. (1991). Methods for dietary fiber, neutral detergent fiber, and nonstarch polysaccharides in relation to animal nutrition. J. Dairy Sci. 74, 3583-3597. doi: 10.3168/jds.S0022-0302(91)78551-2

VDI 4630 (2016). Fermentation of Organic Materials - Characterisation of the Substrate, Sampling, Collection of Material Data, Fermentation Tests. Düsseldorf: Verein Deutscher Ingenieure (VDI).

VDLUFA (2011). Measurement of Biogas and Methane Yields in Fermentation Tests. Darmstadt: Verband Deutscher Landwirtschaftlicher Untersuchungsund Forschungsanstalten (VDLUFA).

Weinrich, S., Schäfer, F., Bochmann, G., and Liebetrau, J. (2018). Value of Batch Tests for Biogas Potential Analysis: Method Comparison and Challenges of Substrate and Efficiency Evaluation of Biogas Plants. Available online at: http://task37.ieabioenergy.com/files/daten-redaktion/download/Technical Brochures/Batch_tests_web_END.pdf

Conflict of Interest: The authors declare that the research was conducted in the absence of any commercial or financial relationships that could be construed as a potential conflict of interest.

Copyright $\odot 2020$ Koch, Hafner, Weinrich, Astals and Holliger. This is an open-access article distributed under the terms of the Creative Commons Attribution License (CC $B Y)$. The use, distribution or reproduction in other forums is permitted, provided the original author(s) and the copyright owner(s) are credited and that the original publication in this journal is cited, in accordance with accepted academic practice. No use, distribution or reproduction is permitted which does not comply with these terms. 